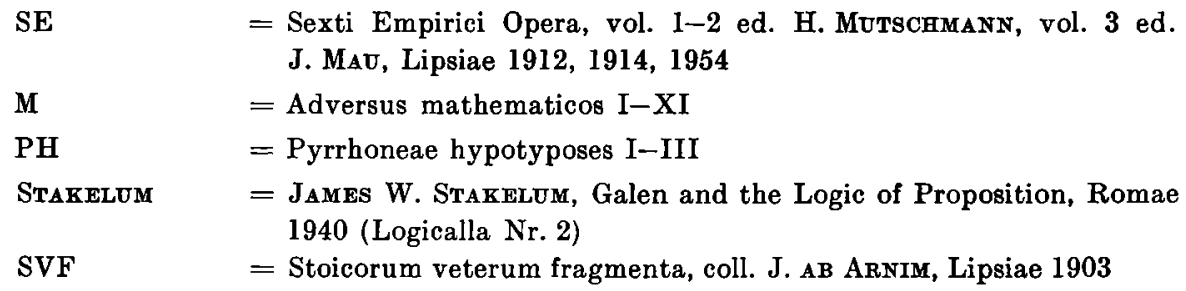

\title{
ERKLÄRUNG DER OFT VERWENDETEN LOGISCHEN SYMBOLE
}

Im Kommentar wird gelegentlich die logistische Schreibweise verwendet, besonders da, wo die Richtigkeit und logische Exaktheit einer Behauptung Galens bewiesen werden soll. Mir schien hierfür die Symbolik EoKasIEwICzs am handlichsten, deren Hauptvorteil das Fehlen von Klammern und Punkten ist. Wendet man diese Symbolik aber konsequent an, dann muß man die alten, uns aus dem berühmten Merkvers geläufigen Konstanten der klassischen Logik (A E I O) fallen lassen, weil drei dieser Buchstaben von EUKASIEwICZ als aussagenlogische Funktoren verwendet werden. Diesen Verzicht leistete BOCHEŃSKI in seiner vortrefflichen 'Logique de Théophraste', zum Schaden der Lesbarkeit. Ich habe sowohl die aussagenlogischen Funktoren EUKAsIewTczs als auch die traditionellen Konstanten beibehalten, indem ich stets dort, wo eine Aussage von einem im Sinne der Syllogistik einfachen Ausdruck (im folgenden termlogisches Urteil), z. B., , $A a b$ " (alle $a$ sind $b$ ) gebildet wird, diese in Klammern gesetzt habe. Es heißt also:

$(A a b):$, Alle $a$ sind $b^{\prime \prime}$

A $p q$ : , Entweder $p$ oder $q^{\prime \prime}$.

Diese Klammern wurden auch dort verwendet, wo die Aussage durch eine mathematische Gleichung o. dgl. gebildet wird. In dem Ausdruck $A p N p$ kann also $p$ ersetzt werden durch z. B. $(1+2=3)$. Noch einmal die Grundregel für das Lesen der EuKasIEwICzschen Symbolik (gute Erklärung: ŁokasIewicz Ar. Syll. 78-79): Die Argumente folgen stets unmittelbar auf ihren Funktor. Es heiBt also z. B.:

$$
C p q \quad \text { "Wenn } p \text {, dann } q^{\prime \prime}
$$

$C K C p q p q \quad$ "Wenn, wenn $p$ dann $q$, und $p$, dann $q^{\text {“ }}$

$C K(A b c)(A a b)(A a c) \quad$,Wenn alle $c c$ sind und alle $a b$ sind, dann sind alle $a$ $c^{" \text { " (Barbara) }}$ 